\title{
REFLEXÕES SOBRE PROFISSIONALIZAÇÃO E IDENTIDADE DOCENTE
}

\section{E. F. PAULA}

Instituto Federal de Educação, Ciência e Tecnologia de São Paulo, Campus de Presidente Epitácio - IFSP/PEP eniodepaula@yahoo.com.br

Artigo submetido em 15/10/2018 e aceito em 07/04/2019

DOI: $10.15628 /$ holos.2016.7846

\section{RESUMO}

Apresentamos a resenha da obra:

TREVIZAN, Z.; DIAS; C.L.; (Orgs). Profissionalização: construção do conhecimento e da identidade docente. Curitiba: CRV, 2012.

PALAVRAS-CHAVE: identidade profissional, profissionalização, formação de professores.

\section{REFLECTIONS ON PROFESSIONALIZATION AND TEACHER IDENTITY}

\section{ABSTRACT}

We present the work's review: TREVIZAN, Z.; DIAS; C.L.; (Orgs). Profissionalização: construção do conhecimento e da identidade docente. Curitiba: CRV, 2012.

KEYWORDS: professional identity; professionalization; teacher education. 


\section{RESENHA}

Em Profissionalização: construção do conhecimento e da identidade docente, encontramos oito artigos escritos por quatorze docentes envolvidos com o Grupo de Pesquisa "Contexto Escolar e Processo de Ensino Aprendizagem: Ações e Interações" - Contepea, vinculado ao programa de Pós-graduação em Educação da Universidade do Oeste Paulista - Unoeste e é dividido em três seções: (1) Contextualização da Profissionalização Docente, composta por três artigos; (2) A Profissionalização em diferentes Concepções Teórico-Pedagógicas, com um artigo e (3) Profissionalização, Trabalho Docente e a Construção do Conhecimento, que reúne quatro artigos.

Não é despretensioso da parte dos autores do artigo de abertura da primeira seção (e consequentemente do livro) "A profissionalização docente: uma revisão de conceitos" afirmarem, em diversas ocasiões no decorrer do texto, que ele se aproxima de um estado da arte, ao revisar, inter-relacionar e estabelecer confrontos epistemológicos entre os conceitos de profissão, profissionalização e proletarização da docência. Para um capítulo de abertura, ele se apresenta extremamente adequado, pois, ao problematizar esses conceitos, levanta um retrospecto histórico da docência. A partir das dificuldades de se definir e caracterizar os elementos essenciais para classificar um(a) determinado(a) ofício/função como profissão, as autoras discutem as mudanças histórico-sociais e político-culturais relacionadas aos processos pelos quais os docentes vivenciaram (e ainda vivenciam) no decorrer do exercício de sua atividade. Entre os autores que permeiam essa discussão, destaca-se o português Antônio Nóvoa. Como os movimentos sociais e as mudanças histórico-cultural-sociais alteraram a maneira como os professores e a escola foram vistos nos últimos três/quatro séculos. Os papeis da escola e os papeis dos professores sofreram grandes mudanças. Entre as problematizações que exemplificam essas mudanças figura a ideia de que "o trabalho docente era visto como semelhante ao trabalho do sacerdote, exigindo dedicação, cuidado, atenção, amor como atividade vocacionada" (BARROS, SCHEIDE, 2012, p.22). Percebemos que essas discussões, fomentadas também em Nóvoa (2000), ainda hoje merecem ser discutidas. A docência vista como vocação, enquanto dom, ainda permeia o discurso das políticas de formação de professores na contemporaneidade brasileira.

A problematização realizada nesse capítulo firma um ponto crucial: a docência está em crise "quando o exercício de uma profissão passa de algo instável, transmitido e assentado em algumas práticas para uma atividade incerta, pouco reconhecida ou problemática, estamos diante de uma crise de identidade" (BOLIVAR, 2002, p.17).

Nessa mesma linha encontramos o artigo Formação de professor e profissionalização: aspectos históricos e contextuais na sequência. A formação docente é vista como um processo contínuo, sem um início pré-determinado e que se (re)constrói no decorrer de suas ações ao longo do tempo. Entre as argumentações presentes nesse segundo artigo, das quais compartilhamos, destaca-se a afirmação de que os momentos de formação de professores não estão restritos à formação inicial: a formação se dá em processos complexos, multifacetados e plurais. Eles envolvem elementos anteriores a formação inicial e se estendem para além dela. 
Um fator interessante e justificador, apontado pela autora para conceber esse texto, é a necessidade de uma contextualização histórica da profissão docente articulada com as reflexões a respeito das mudanças e dos desafios que a escola enfrenta na atualidade. A ideia de que a profissão docente envolve a aprendizagem e o desempenho de dois papeis inter-relacionados - 0 papel de ensinar e o papel de ser professor - merece destaque nesse texto: em ambos os papeis há implícitas e explicitas dificuldades/empecilhos historicamente construídos.

Dentro dessa diversidade que envolve os movimentos, em especial no Brasil, pertinentes às reformas educacionais diretamente relacionados à formação de professores, a autora problematiza o quadro proposto por Hunt (2008), em seu estudo sobre a eficácia e desempenho docente. A ideia(I) de um professor modelo, eficaz e competente, "formado" segundo critérios esperados (relacionados aos seus conhecimentos, atitudes e desempenho) está envolta em contradições e comparações pautadas em avalições de rendimentos dos alunos. Isso significa ver o professor, como a própria autora diz, enquanto um super-herói, e esse fato, além de acentuar a precarização do trabalho, intensifica as exigências e o rigoroso controle burocrático das práticas docentes. A autora finaliza com a ideia de que a formação (os investimentos e as necessidades para) não é uma questão técnica, nem decorrente de um movimento linear ou hierárquico e defende que a profissionalização "deve ser compreendida, para além de um ofício, com perspectivas atuais e futuras de reconhecimento, de remuneração digna, de sustentação da própria sobrevivência do professor e de sua família, de condições dignas de trabalho (RINALDI, 2012, p. 44)".

O ensaio Ética e educação: um sentido (mais) humano para a docência finaliza composição da primeira parte da obra. Os autores debatem os sentidos comumente associados ao ensino de ética: associá-la a como um tema transversal (como exposto nos Parâmetros Curriculares Nacionais) ou enquanto conteúdo específico de uma disciplina (geralmente em cursos de Medicina, Direito ou da área administrativa/empresarial).Ao apresentarem um breve histórico desses sentidos no contexto brasileiro: da presença dos valores nacionalistas, cristãos e morais na lendária disciplina "Educação Moral e Cívica", perpassando pelos documentos recentes que buscam estabelecer relações entre a ética, a criticidade e a alteridade, em uma sociedade cada vez mais apática, insensível e alheia à coletividade, mas individualista e preocupada em buscar/manter privilégios. A proposta dos autores é "Pensar a ética na sala de aula não meramente como forma de um ensino, mas também em sua efetivação real na atuação do professor" (Brocanelli, Carvalho, 2012, p. 54). As dimensões epistemológica, ética, política, altruísta são problematizadas a partir do conceito filosófico de amizade, inter-relacionando o ambiente escolar e seus viventes. A compreensão da alteridade e da amizade, segundo os autores, em meio a um mundo que insiste/persiste com seus dilemas, sugere que o enfrentamento das dificuldades seja realizado por meio do diálogo e do ato de colocar-se no lugar do outro. Explorar (e fomentar) as intersubjetividades é um caminho a ser percorrido.

Como dissemos no início, a segunda seção do livro é constituída por um único artigo, denso e articulado: $A$ profissão docente em diferentes concepções teórico-pedagógicas: os enfoques tradicionalista, construtivista e sócioconstrutivista que se apresenta como o maior artigo do livro. Nele é apresentado um estudo de natureza bibliográfica pautado em uma análise que objetiva compreender, no contexto da educação brasileira, as implicações e articulações desses três 
enfoques com o exercício da profissão docente. Um ponto interessante é que as reflexões caminham no sentido de problematizar o fato de que os inúmeros compromissos diários assumidos como garantia de sua sobrevivência do trabalhador-professor, são a ele impeditivos de uma vida intelectual e cultural ativa. Esse fato é um dos condicionantes para as bruscas mudanças no trabalho docente.

A terceira seção reúne artigos que tratam de maneira mais intimista áreas especificas do conhecimento. Em A profissionalização e o trabalho docente na formação de leitores, artigo de abertura dessa seção, a autora amplia as discussões de uma pesquisa do próprio grupo (Contepea) intitulada "Profissionalização e Trabalho Docente: Identidade e Representação Social", realizada em uma escola de Educação Básica do interior paulista. $O$ artigo é articulado em duas partes que relacionam publicações oriundas desse trabalho grupal. Na primeira parte do artigo, por meio da análise semiótica das falas dos professores, entre os resultados apresentados, constatam-se as idiossincrasias e anseios docentes em vivenciarem uma prática crítico-reflexiva e seus posicionamentos a respeito da influência dos diversos contextos no decorrer de suas práticas profissionais. Na segunda parte a autora dá continuidade às reflexões da primeira e, vinculando as reflexões especificamente aos comprometimentos da prática docente com o ensino da leitura intrinsicamente relacionais, a construção de sua autonomia e identidade docente. Reflexões a respeito das visões estereotipadas do exercício da docência (aqueles que não a veem como profissão, mas como um dom/missão/afeto) são problematizadas no decorrer do artigo.

O artigo Narrativas de professoras: um olhar sobre si e sobre a profissão docente apresenta resultados de uma pesquisa pautada na abordagem autobiográfica e a investigação de arquivos escolares (documentais e fotográficos), cujo objetivo fora traçar um perfil de uma escola do interior paulista. O recorte das pesquisadoras tem o intuito de problematizar aspectos evidenciados nas autobiografias das mulheres professoras entrevistadas nesse contexto, que remetem às ações de (des)valorização da prática docente, às questões de gênero, afetividade entre professor-aluno-escola e a busca por igualdade por parte dessas mulheres.

Na sequência, A profissionalização e o trabalho docente no desenvolvimento do raciocínio geográfico discute as especificidades da formação e ação do professor de geografia no sentido de desvelar, em suas práticas profissionais, a leitura de mundo capaz de problematizar as complexidades do mundo atual. A autora parte das reflexões a respeito das bases teóricas e metodológicas da formação docente (bem como as diretrizes curriculares voltadas à formação do professor de geografia) e estabelece articulações entre os conhecimentos geográfico e pedagógico, necessários a esse profissional.

$\mathrm{O}$ artigo que fecha a terceira parte e consequentemente o livro, $A$ docência $e$ o conhecimento matemático: anotações para reflexão faz uma defesa da matemática e sua importância para o desenvolvimento do pensamento humano. Nesse texto, reflexões a respeito dos sensos ético e estético alusivos às particularidades dos conhecimentos relacionados à Matemática enquanto Ciência (o que ela é, do que trata, a quem interessa, como se relaciona com as demais áreas, em suas múltiplas facetas). A argumentação dos autores caminha para justificar a presença e a necessidade da Matemática como uma linguagem matemática fundamental para a compreensão e leitura de mundo. "A docência em Matemática parece clamar por um novo espírito, menos submisso à paixão pela exatidão de suas respostas e mais propenso a múltiplas 
leituras de um mundo aberto ao encantamento (RUIZ, SCHEIDE, 2012, p. 176). Para os autores, essa nova visão "acarretaria o enriquecimento da identidade do professor, ligando-o às perspectivas da construção do conhecimento matemático (RUIZ, SCHEIDE, 2012, p. 176)". A matemática é vista como um meio capaz de ampliar a leitura da realidade, favorecendo a compreensão de sistemas de natureza complexa. As referências desse texto envolvem muitos livros clássicos de divulgação científica, que associam a Matemática às Ciências e à criatividade enquanto elementos relevantes para o avanço da cultura humana. Sem dúvida, trata-se de um texto que defende a Matemática, o professor que ensina matemática e uma visão de matemática irrestrita às suas tecnicidades. Um dos autores tem um histórico na defesa dessas ideias em outras publicações (RUIZ, 2005, 2011, 2015).

Ao finalizarmos a leitura da obra, é preciso destacarmos alguns pontos que, de modo amplo, apresentam-se como articuladores das reflexões a respeito da identidade docente. Um deles é ressaltar as interferências das influências do processo de produção capitalista nas relações de trabalho docente: sua lógica mercantilista fomenta o parcelamento e a excessiva rotinização das tarefas profissionais, o que ocasiona uma planificação de sua evolução funcional (ou seja, ela não acontece). Essas influências desencadeiam vulnerabilidades que fragilizam o docente e comprometem sua autonomia profissional. Outro ponto está relacionado ao reconhecimento social da profissão. A ideia do exercício da docência enquanto complementação de renda, de baixos salários, remonta, entre outros consequentes, à associação do exercício da docência como uma função estritamente feminina, na qual - aos olhos de uma sociedade (então?) machista, patriarcal e secular - como a mulher não era a "provedora do lar", sua remuneração deveria ser menor. Essa triste visão não cabe nos dias de hoje (e nem deveria caber no passado).

Os esforços em discutir a identidade docente presentes nos artigos integrantes da obra, evidenciam a formação de professores enquanto um campo de luta ideológica e política que carece ser problematizado. Em tempos de reformas, como estes em que vivemos, no qual novas políticas e diretrizes a respeito da formação, do papel da escola e do professor estão em jogo, a leitura de Profissionalização: construção do conhecimento e da identidade docente é uma opção sensata.

\section{REFERÊNCIAS}

Barros, H.F.; Scheide, T.J.F. (2012). A profissionalização docente: uma revisão de conceitos. In Trevisan, Z.; Dias, C.L. (Org.). (2012) Profissionalização: Construção do Conhecimento e da Identidade do Docente. Curitiba: CRV.

Bolívar, A. (2002). Competências profissionais e crise de identidade. Porto Alegre, Pátio, IV (23), 1619.

Brocanelli, C.R.; Carvalho, A.B. (2012). Ética e educação: um sentido (mais) humano para a docência. In Trevisan, Z.; Dias, C.L. (Org.). (2012). Profissionalização: Construção do Conhecimento e da Identidade do Docente. (1a ed., pp. 49-70). Curitiba: CRV. 
HUNT, B.C. (2008). ¿ Qué disse la literatura internacional sobre la efetividad del desempenõ docente? PREAL: Formas \& Reformas de La Educacíon, N. 30, pp. 1-4.

NÓVOA, A. (Org.). (2000). Vida de Professores. Porto: Porto Editora.

RINALDI, R.P. (2012). Formação de professor e profissionalização: aspectos históricos e contextuais. In Trevisan, Z.; Dias, C.L. (Org.). Profissionalização: Construção do Conhecimento e da Identidade do Docente. ( Vol. 1, pp. 33-48.). Curitiba: CRV.

Ruiz, A.; Scheide, T. J. F. (2012). A docência e o conhecimento matemático: anotações para reflexão. In Trevisan, Z.; Dias, C.L. (Org.). Profissionalização: Construção do Conhecimento e da Identidade do Docente. (1ed., pp. 163-178). Curitiba: CRV.

Ruiz, A. R. (2015). A Autoria entre o apreço e a renúncia. Revista Teias (UERJ. Online), Vol. 16, 3646.

Ruiz, A. R. (2005). Ciência e sua iniciação: anotações para reflexão. Ciência e Educação (UNESP), Bauru, Vol. 11, pp. 319-326.

Ruiz, A. R. (2011). O que é a matemática?. Revista Teias (UERJ. Online), Vol. 12, pp. 287-297. 